\title{
Aka Canturk Oral Autopsy Method for the Dental Identification of Fetus and Infant Cases
}

\author{
P. Sema Aka1, Nergis Canturk ${ }^{2 *}$ \\ ${ }^{1}$ Head of Forensic Odontology Commission of Turkish Forensic Scientists Society, Retired Professor of Ankara \\ University, Ankara, Turkey \\ ${ }^{2}$ Department of Criminalistics, Institute of Forensic Sciences, University of Ankara, Ankara, Turkey \\ Email: akasema@gmail.com, ${ }^{*}$ nergiscanturk@yahoo.com
}

Received 30 April 2014; revised 5 June 2014; accepted 19 June 2014

Copyright (C) 2014 by authors and Scientific Research Publishing Inc.

This work is licensed under the Creative Commons Attribution International License (CC BY). http://creativecommons.org/licenses/by/4.0/

c) (i) Open Access

\begin{abstract}
Forensic research requires the application of reliable identification methods for unidentified individuals, among which the dental analysis has prime importance. The most significant source of dental evidence is oral autopsy applications, which consist of an examination and evidence collection from the oral cavity of a deceased individual. Oral autopsies show variations depending on the age of the person due to rigor mortis. The oral autopsy of a child may require an easier operation than adults, and thus, the procedures are usually simpler for fetus or infant cases. The aim of this study is to propose the theoretical and experimental aspects of an oral autopsy protocol for a special age group of fetus or infant cases, which is a method for extracting tooth germs in their developmental stages for identification purposes and entitled by the authors' names as the "Aka-Canturk Oral Autopsy Method".
\end{abstract}

\section{Keywords}

Oral Autopsy, Fetus, Infant, Dental Identification, Age Estimation

\section{Introduction}

Forensic odontological research covers an important aspect of the forensic sciences, which consist of an extraand intra-oral examination during the oral autopsy and the collection of dental evidence to identify deceased persons and human remains. The oral autopsy shows variations depending on the age of the person due to rigor

Corresponding author. 
mortis. In particular, adult autopsies require operations, such as skin dissection or jaw removal to obtain a visual scope for non-viewable cases [1]-[4]. On the contrary, child autopsy procedures are usually uncomplicated due to the muscle weakness. It has been stated that oral autopsy protocols may be modified according to special situations [5]; however, a germ extraction protocol for fetus or infant cases has not yet been defined in the literature. Therefore in the current study, the protocol of oral autopsies applied to fetus and infant cases, which consists of a method for extracting the tooth germs in their developmental stages for accurate age estimation, is defined as the "Aka-Canturk Oral Autopsy Method".

\section{Materials and Methods}

This study was conducted with under legal and ethical permission (The Council of Forensic Medicine, number and date: B.03.1.ATK.0.01.00.08/237, May 30, 2006) and the Ethics Committee of Ankara University, Turkey: Number and date: 103 - 2692, December 4, 2006). The oral autopsy process of fetus and infant cases requires routine surgical hand instruments and the following list of equipment, depending on the choice of the forensic odontologist:

1) Photograph machine, alternative light sources, and scale (ABFO Number 2 Scale);

2) Swab materials;

3) Digital compasses (Vernier compass, sensitive to $0.1 \mathrm{~mm}$ (Mitutoyo 7117057, Japan), digital thickness gauge (Fara Dental, Taster Zirkel Nach Iwanson-Ref. 21821, Ellwangen, Germany);

4) Portable x-ray machine;

5) Dental charts, forms, autopsy report form;

6) Retractors;

7) Straight and curved luxating elevators, apical elevators;

8) Preserving solutions, and;

9) Properly labelled containers for the teeth samples of each quadrant.

Oral autopsy applications must be performed by two experts and an assistant who is responsible for recording the data. One of the experts must be a forensic odontologist and the other preferably a forensic medicine specialist. The following are the requirements under which an autopsy is performed:

1) Proper written authorization to conduct the oral autopsy examination;

2) Routine autopsy clothing;

3) Double swab must be taken from the oral cavity and kept at room temperature if submitted within 4 - 6 hours, or refrigerated (not frozen) if stored longer than 6 hours according to the "American Board of Forensic Odontology" [6];

4) Photographs must be recorded during the examinations;

5) Complete recording with labeled radiographs, photos, charts, impressions, models, and tooth samples;

6) Curved incisions are made following the ridges of maxillary and mandibular alveolar crests, and the periosteum must be separated from the bone;

7) Extraction of teeth must be done with the application of the elevators from the mesial sites of the periodontal socket, without making any contact with the tooth germ, and the tooth bud specimen is placed in properly labeled containers filled with preserving solutions (10\% formalin solution, $1 \%$ phenol, or $10 \%$ sodium hypochlorite) [7];

8) All deciduous teeth germs can be extracted for diagnostic identification purposes and photographed. This evidence is then preserved in the event of burial or cremation of the body. However, in the case an erupted tooth is present, it can be measured in-situ and recorded [8] [9];

9) When required, the selected tooth specimens can be sent for scanning electron microscope (SEM) examinations to detect the neonatal line to determine the viability of the deceased fetus at the time of birth [10];

10) Finally the dental forms and charts are completed and a detailed oral autopsy report should be prepared. Copies of all the original documents related to the case must be saved by the forensic odontologist [5].

\section{Discussion and Conclusions}

Dental evidence is a reliable source of identification for unknown deceased individuals, which usually necessitate oral autopsy procedures. A solid result can be obtained when the findings of the dental examination are combined with the data of the medical autopsy. Therefore, the establishment of a "Forensic Odontology Unit" is 
recommended for all morgue departments.

Oral autopsies for adults are complicated operations requiring the dissection of soft tissue and muscles, plus the removal of mandible and/or maxilla for clear observation of the oral cavity, in the presence rigor mortis, which closes access [2]. Dental evidence obtained from these operations may be deflashed with $3 \%$ - $6 \%$ sodium hypochlorite and preserved [11] [12]. The identification by age estimation from permanent adult teeth is also a complex procedure and may require the application of various techniques on the extracted permanent teeth, such as scanning electron microscope (SEM) and light microscope studies [13]-[15]. Age estimation from deciduous teeth is a simpler and straightforward implication, especially for dental arches where the teeth are unerupted.

Oral autopsies for fetus and infant cases have importance, especially in criminal abortions, for bodies found in mass disasters, miscarriages, and abandoned cases. The "Aka-Canturk Oral Autopsy Method" is a relevant method, which does not require any skin dissection or jaw removal, as the muscles are weaker and access to the oral cavity is effortless. Age estimation by applying age formulas to physical tooth measurement data is an accurate method [8] [9]. Age estimation is based upon the development of the dentition, and therefore cannot be applied after the completion of dental development. The only disadvantage of this technique is damaging the tooth specimen when required for SEM investigations. This technical note explains a simple, reliable, and accurate oral autopsy protocol for fetus and infant cases entitled the "Aka-Canturk Oral Autopsy Method," which requires minor intervention in acquiring the dental evidence.

\section{References}

[1] Inanici, M.A., Cagdir, S., Birgen, N. and Soysal, Z. (2000) Dis Muayenesi ile Kimligin Saptanmasi ve Agiz ici Otopsi Uygulamasi [Identity Determination with Dental Examination and Oral Autopsy]. Akademik Dental Dis Hekimligi Dergisi [Academic Journal of Dental Dentistry], 2, 1-6.

[2] Fereira, J., Ortega, A., Avila, A., Espina, A., Leendertz, R. and Barrios, F. (1997) Oral Autopsy of Unidentified Burned Human Remains. A New Procedure. American Journal of Forensic Medicine \& Pathology, 18, 306-311. http://dx.doi.org/10.1097/00000433-199709000-00017

[3] Soysal, Z., Eke, S.M. and Cagdir, A.S. (1999) Forensic Autopsy. 1st Edition, Istanbul University, Istanbul.

[4] Afsin, H. (2004) Forensic Odontology. 1st Edition, Institute of Forensic Medicine Publishs, Istanbul.

[5] Stimson, P.G. (2013) Oral Autopsy Protocol. Dental Clinics of North America, 21, 177-179.

[6] American Board of Forensic Odontology (2014) Diplomates Reference Manual, 72-112. http://www.abfo.org/wp-content/uploads/2012/08/ABFO-Reference-Manual-1-22-2013-revision.pdf

[7] Van Beek, G.C. (2008) Dental Morphology: An Illustrated Guide. 2nd Edition, Elsevier, Philadelphia.

[8] Aka, P.S., Canturk, N., Dagalp, R. and Yagan, M. (2009) Age Determination from Central Incisors of Fetuses and INFANTs. Forensic Science International, 184, 15-20. http://dx.doi.org/10.1016/j.forsciint.2008.11.005

[9] Dagalp, R., Aka, P.S., Canturk, N. and Kedici, I. (2013) Age Estimation from Fetus and Infant Tooth and Head Measurements. International Journal of Legal Medicine, 128, 501-508. http://dx.doi.org/10.1007/s00414-013-0935-3

[10] Canturk, N., Atsu, S.S., Aka, P.S. and Dagalp, R. (2014) Neonatal Line on Fetus and İnfant Teeth: An İndicator of Live Birth and Mode of Delivery. Early Human Development, 90, 393-397.

[11] Silver, E.W. and Souviron, R.R. (2009) Dental Autopsy. CRC Press Taylor \& Francis Group, Boca Raton. http://dx.doi.org/10.1201/9781420070163

[12] Mann, R.W. and Berryman, H.E. (2012) A Method for Defleshing Human Remains Using Household Bleach. Journal of Forensic Sciences, 57, 440-442. http://dx.doi.org/10.1111/j.1556-4029.2011.01987.x

[13] Atsu, S.S., Gokdemir, K. and Kedici, P.S. (1998) Human Dentinal Structure as an Indicator of Age. The Journal of Forensic Odonto-Stomatology, 16, 27-29.

[14] Kedici, P.S., Atsu, S.S., Gokdemir, K., Sarikaya, Y. and Gurbuz, F. (2000) Micrometric Measurements by Scanning Electron Microscope (SEM) for Dental Age Estimation in Adults. The Journal of Forensic Odonto-Stomatology, 18, 22-26.

[15] Atsu, S.S., Aka, P.S. and Nergis, I. (2006) Age Estimation from Root Transparency. Turkiye Klinikleri J Dental Sci, 12, 47-52. 